\title{
Insulin encapsulation in reinforced alginate microspheres prepared by internal gelation
}

\author{
Catarina M. Silva ${ }^{a, *}$, António J. Ribeiro ${ }^{b}$, Domingos Ferreira ${ }^{c}$, Francisco Veiga ${ }^{a}$ \\ a Laboratory of Pharmaceutical Technology, Faculty of Pharmacy, University of Coimbra, \\ Rua do Norte, 3000-295 Coimbra, Portugal \\ $\mathrm{b}$ Laboratory of Pharmaceutical Technology, North Health Sciences Superior Institute, \\ Rua Central de Gandra 1317, 4585-116 Gandra, Paredes, Portugal \\ c Laboratory of Pharmaceutical Technology, Faculty of Pharmacy, University of Oporto, \\ Rua Aníbal Cunha 164, 4050-047 Oporto, Portugal
}

\section{A R T I C L E I N F O}

\section{Article history:}

Received 6 March 2006

Received in revised form 21 June

2006

Accepted 25 June 2006

Published on line 29 June 2006

\section{Keywords:}

Alginate microspheres

Chitosan

Insulin release

Internal gelation

Anionic polyelectrolytes

\begin{abstract}
A B S T R A C T
Insulin-loaded alginate microspheres prepared by emulsification/internal gelation were reinforced by blending with polyanionic additive polymers and/or chitosan-coating in order to increase the protection of insulin at simulated gastric $\mathrm{pH}$ and obtain a sustained release at simulated intestinal $\mathrm{pH}$. Polyanionic additive polymers blended with alginate were cellulose acetate phtalate (CAP), Eudragit ${ }^{\circledR}$ L100 (EL100), sodium carboxymethylcellulose (CMC), polyphosphate (PP), dextran sulfate (DS) and cellulose sulfate (CS). Chitosan-coating was applied by using a one-stage procedure. The influence of additive polymers and chitosancoating on the size distribution of microspheres, encapsulation efficiency and release profile of insulin in simulated gastrointestinal pH conditions was studied. The mean diameter of blended microspheres ranged from 65 to $106 \mu \mathrm{m}$ and encapsulation efficiency of insulin varied from 14 to $100 \%$, reaching a maximum value when CS and DS were incorporated in the alginate matrix. Insulin release, at pH 1.2, was almost prevented by the incorporation of $\mathrm{PP}$, DS and CS. When uncoated microspheres were transferred to $\mathrm{pH} 6.8$, a fast dissolution occurred, independently of the additive polymer blended with alginate, and insulin was completely released. Increasing the additive polymer concentration in the alginate matrix and/or chitosan-coating the blended alginate microspheres did not promote a sustained release of insulin from microspheres at $\mathrm{pH} 6.8$.
\end{abstract}

() 2006 Elsevier B.V. All rights reserved.

\section{Introduction}

Insulin is a therapeutically active protein of great interest for its broad use in the treatment of diabetes mellitus. The optimal method of insulin delivery should be safe and correct the metabolic abnormalities of diabetes, and must be psychologically and socially acceptable (Brange and Langkjaer, 1997). However, in clinical therapy, insulin is mainly administered via the subcutaneous route which is associated with local discomfort and multiple administrations. Another disadvantage is occasional hyperinsulinaemia due to overdose because insulin is administered in a non-physiological way, targeting mainly extrahepatic insulin-dependent tissues. Since the principal organ in glucose homeostasis is the liver this should logically be the prime target for intervention (Arbit, 2004). Furthermore, the oral route is considered to be the most acceptable

\footnotetext{
* Corresponding author. Tel.: +351 239 855085; fax: +351 239855099.

E-mail address: catarinasilva@ci.uc.pt (C.M. Silva).

0928-0987/\$ - see front matter @ 2006 Elsevier B.V. All rights reserved. doi:10.1016/j.ejps.2006.06.008
} 
and convenient route of drug administration for chronic therapy.

One major problem associated with the oral delivery of insulin is its low bioavailability due to the proteolytic activity of the acidic juice in the stomach, susceptibility to enzymatic attack by intestinal proteases and peptidases, poor intrinsic permeability across biological membranes, rapid postabsorptive clearance and chemical and physical instability (Sood and Panchagnula, 2001).

Several attempts have been proposed to improve oral bioavailability, among them microencapsulation represents a promising concept (Carino and Mathiowitz, 1999). The encapsulated insulin may be protected against proteolytic attack in the physical environment of the formulation itself and microparticles may release the peptide at or near the cellular membrane to optimize the driving force for passive permeation. A mild encapsulation method should be adopted to guarantee the preservation of the native protein structure during preparation, storage and release. In order to minimize protein denaturation or aggregation and loss of its biological activity, the exposure to high temperatures, high shearing or organic solvents should be avoided (van de Weert et al., 2000).

In a previous work from our group, insulin was encapsulated in alginate microspheres prepared by the emulsification/internal gelation method (Silva et al., 2006). Alginate is a biodegradable, biocompatible, non-toxic and naturally occurring polysaccharide composed of $\alpha$-L-guluronic $(G)$ and $\beta$-Dmannuronic $(\mathrm{M})$ acids. Alginate solution forms a gel matrix, in mild conditions, in the presence of divalent ions, such as $\mathrm{Ca}^{2+}$. This gelation is known to arise primarily at junctions ("egg-box junctions") in G-G-sequence rich chain regions (G-blocks). In the emulsification/internal gelation method, alginate solution containing an insoluble calcium salt is dispersed in oil to form a water/oil (w/o) emulsion and gelation is achieved by gentle acidification with an oil-soluble acid that causes calcium ion release. This technique proved to be appropriate to maintain insulin biological stability, since insulin extracted from the microspheres induced a hypoglycemic effect following its subcutaneous administration to diabetic rats (Silva et al., 2006). This formulation was also evaluated in simulated gastrointestinal $\mathrm{pH}$ conditions to determine its suitability for oral administration. However, insulin was released before reaching the intestinal $\mathrm{pH}$, where absorption should occur. A high insulin release, near $80 \%$, was obtained at $\mathrm{pH} 1.2$, which means that alginate microspheres by themselves could not protect insulin from the gastric environment.

Gel matrix of calcium alginate microspheres is usually very permeable having a low retention capacity of encapsulated molecules due to its $\mathrm{pH}$ dependent solubility (Gursoy and Cevik, 2000). There have been made numerous efforts to control the erosion of alginate microspheres and extend drug release. The most commonly investigated approach consists in coating microspheres with polycationic polymers such as chitosan (Anal and Stevens, 2005; Ribeiro et al., 2005) or polyL-lysine (Cui et al., 2001; Ueng et al., 2004). Another approach to control the drug release from alginate microspheres consists in blending alginate with other polymers, such as, cellulosic derivatives (El-Kamel et al., 2003), acrylic polymers (Iruin et al., 2005), pectin (Pillay et al., 2005), chitosan (Murata et al., 2003), polyvinylpyrrolidone (Chan and Heng, 1998), chondroitin sulfate (Murata et al., 1996) or gelatine (Almeida and Almeida, 2004). In the case of peptide drugs, such as insulin, the prevention of insulin release at simulated gastric $\mathrm{pH}$ and a sustained release at simulated intestinal $\mathrm{pH}$ are considered desirable.

The purpose of this work was to encapsulate insulin in alginate microspheres prepared by emulsification/internal gelation reinforced by blending alginate with other polymers and/or coating microspheres with a polycation. The preservation of optimal characteristics of size distribution and encapsulation efficiency was a concern. Anionic polyelectrolytes were selected as blending polymers and chitosan was chosen as polycation. Polyanionic additive polymers were chosen for blending with alginate, due to the fact that having the same charge as alginate will prevent an interaction between the two polymers, which could interfere with the microspheres preparation by emulsification/internal gelation. Furthermore, it has been observed that the interaction between alginate and insulin is very important to assure a high insulin encapsulation efficiency (Silva et al., 2006). The addition of another polyanion should not interfere with this interaction and may, on the contrary, contribute to reinforce it. The influence of formulation on insulin release from microspheres was evaluated in simulated gastrointestinal $\mathrm{pH}$ conditions and the retention of insulin at gastric $\mathrm{pH}$ was considered critical in selecting an optimized formulation, so that insulin could not be released before reaching its absorption site, the small intestine. The achievement of a sustained release at simulated intestinal $\mathrm{pH}$ was also an objective, in order to reduce the potential degradation of insulin before absorption and to profit from the bioadhesive properties of alginate (Chickering et al., 1997) and chitosan (Lehr et al., 1992), which may increase the residence time in the upper small intestine.

\section{Materials and methods}

\subsection{Materials}

Sodium alginate (Algogel ${ }^{\circledR}$ 3541) was obtained from Degussa Texturant Systems (Boulogne-Billancourt, France). This alginate presented a viscosity measured with a rotational viscometer (Visco Star plus, Fungilab, S.A., Barcelona, Spain) for a $1 \%$ solution at $20^{\circ} \mathrm{C}$ of $318 \mathrm{mPas}$. Cellulose sulfate, dextran sulfate, polyphosphate, sodium carboxymethylcellulose and Eudragit ${ }^{\circledR}$ L100 were supplied by Acros Organic (Geel, Belgium) Sigma (Steinheim, Germany), Riedel-de-Haën (Steinheim, Germany), Akzo Nobel (Amersfoot, Netherlands) and Rhöm Pharma Polymers (Darmstadt, Germany), respectively. Cellulose acetate phthalate and paraffin oil were purchased from Vaz Pereira (Lisbon, Portugal). Low molecular weight chitosan, having around $150 \mathrm{kDa}$ (supplier specification), and sorbitan monooleate $\left(\operatorname{Span}^{\circledR} 80\right.$, HLB $4.3 \pm 1$ ) were purchased from Fluka Chemie GmbH (Buchs, Switzerland). Calcium carbonate (Setacarb ${ }^{\circledR} 06$ ) was supplied by Omya (Orgon, France). Insulin was obtained as a regular human insulin of recombinant DNA origin (Actrapid ${ }^{\circledR} 100 \mathrm{IU} / \mathrm{ml}$ ) from Novo Nordisk A/S (Bagsvaerd, Denmark). All other chemicals used were of analytical reagent grade. 


\subsection{Methods}

\subsubsection{Preparation of microspheres}

Microspheres were prepared by emulsification/internal gelation as described in a previous work (Silva et al., 2006). Briefly, a $2 \%(\mathrm{w} / \mathrm{v})$ sodium alginate solution was prepared by dissolution of the polymer in an insulin solution at $0.1 \%(\mathrm{w} / \mathrm{v})$. In additive polymer-blended microspheres, a polyanionic additive polymer was dissolved in the alginate solution at 0.5 or $1 \%(\mathrm{w} / \mathrm{v})$. Additive polymers included cellulose acetate phthalate (CAP), Eudragit ${ }^{\circledR}$ L100 (EL100), sodium carboxymethylcellulose (CMC), polyphosphate (PP), dextran sulfate (DS) and cellulose sulfate (CS). Viscosity measurements of the alginate:additive blends were performed using a rotational viscometer (Visco Star plus, Fungilab, S.A., Barcelona, Spain), at $22^{\circ} \mathrm{C}$.

A suspension of $5 \%(\mathrm{w} / \mathrm{v})$ ultrafine $\mathrm{CaCO}_{3}$ was added to the polymer solution to obtain a calcium/alginate ratio $(w / w)$ of $7.3 \%$ and, after homogenization, the mixture was dispersed into paraffin oil (30\% internal phase ratio, v/v) containing $1 \%$ Span ${ }^{\circledR} 80$ by stirring at $400 \mathrm{rpm}$ using an Ika-Eurostar ${ }^{\circledR}$ mixer (Ika, Staufen, Germany) equipped with a marine impeller. The emulsion was formed in a round-bottomed cylindrical glass reaction vessel. After $15 \mathrm{~min}$ of emulsification, $20 \mathrm{ml}$ of paraffin oil containing glacial acetic acid was added to the w/o emulsion to obtain an acetic acid/calcium molar ratio of 3.5 and stirring continued to permit $\mathrm{CaCO}_{3}$ solubilization. Gelled microspheres were recovered from oily phase by using an acetate buffer at $\mathrm{pH} 4.5$ (United States Pharmacopeia [USP] XXVIII) and successively washed with this buffer until no more oil was detected by optical microscope observation.

Chitosan-coating was applied by using a continuous microencapsulation procedure designated as one-stage coating (Ribeiro et al., 2005). An emulsion of $0.1 \%(\mathrm{w} / \mathrm{v})$ of acetate chitosan at $\mathrm{pH} 4.5$, in paraffin oil $(50 / 50, \mathrm{v} / \mathrm{v})$ containing $1 \%$ Span $^{\circledR} 80$, was added to the oily-dispersed gelled microspheres and stirring was performed for $30 \mathrm{~min}$. Coated microspheres were recovered as described above.

Microspheres were frozen in an ethanol bath (Benchtop shell freezer, Freezone ${ }^{\circledR}$ model 79490, Labconco, Kansas City, MS, USA) at $-50^{\circ} \mathrm{C}$ and freeze-dried (Lyph-lock 6 apparatus, Labconco) at $0^{\circ} \mathrm{C}$ for, at least, $48 \mathrm{~h}$.

\subsubsection{Morphological and particle size analysis}

An optical microscope Olympus BH2-UMA equipped with a Cue-2 image analyser (Olympus, Tokyo, Japan) was used to study microsphere morphology. The shape and surface texture of microspheres was examined by scanning electron microscopy (SEM) (JEOL JSM-840 ${ }^{\circledR}, 10 \mathrm{kV}$, Tokyo, Japan). The samples were mounted on metal stubs, using double sided adhesive tape, gold coated under vacuum and then examined.

Granulometric size distribution was determined in washing media by laser diffractometry (Fraunhofer model) using a Coulter LS130 particle analyser (Beckman Coulter Inc., Fullerton, CA, USA), with a size range from 0.1 to $1000 \mu \mathrm{m}$. Particle size is expressed as volume mean diameter $(\mu \mathrm{m}) \pm$ S.D. values of the mean. Measurements were made in triplicate for each batch. Polydispersity was determined by the SPAN factor (El-Mahdy et al., 1998) expressed as SPAN $=[D(v, 90)-D(v, 10)] / D(v, 50)$, where $D(v, 90), D(v, 10)$ and $D(v, 50)$ are volume size diameters at 90,10 and $50 \%$ of the cumulative volume, respectively. A high value of SPAN indicates a wide distribution in size and a high polydispersity.

\subsubsection{Insulin content and encapsulation efficiency}

To determine the insulin content, $5 \mathrm{mg}$ of lyophilized insulinloaded microspheres were accurately weighed and incubated in $5 \mathrm{ml}$ of phosphate buffer at pH 7.4 (USP XXVIII), containing $0.1 \mathrm{M}$ ethylenediamine tetra-acetic acid (EDTA), under magnetic stirring $(100 \mathrm{rpm} / 2 \mathrm{~h})$. Samples were withdrawn after incubation and analysed for insulin content by high performance liquid chromatography (HPLC). Insulin content (\%, $\mathrm{w} / \mathrm{w}$ ) was defined as the amount of insulin (mg) in $100 \mathrm{mg}$ of microspheres. The encapsulation efficiency (\%) of insulin was calculated from the ratio between the actual insulin content and the theoretical insulin content. Assays were performed in triplicate.

\subsubsection{In vitro release studies}

A multiple stirring points plate was used for in vitro release studies. Insulin-loaded microspheres $(20 \mathrm{mg})$ were placed in $20 \mathrm{ml}$ of hydrochloric acid buffer at pH 1.2 (USP XXVIII) and stirred at $100 \mathrm{rpm}$. After $2 \mathrm{~h}$, the microspheres were transferred to $20 \mathrm{ml}$ of phosphate buffer at $\mathrm{pH} 6.8$ (USP XXVIII) and incubated for $4 \mathrm{~h}$. Two millilitre of sample was taken at appropriate intervals from both media and insulin content was determined by HPLC. Assays were performed in triplicate.

\subsubsection{Insulin analysis}

Samples withdrawn from hydrochloric acid buffer at $\mathrm{pH} 1.2$ were centrifuged $(13,400 \mathrm{rpm} / 10 \mathrm{~min})$ and the supernatant was used for insulin analysis. Samples obtained from phosphate buffer at $\mathrm{pH} 6.8$ were mixed with $0.2 \mathrm{M} \mathrm{NaOH}$, to raise $\mathrm{pH}$ above 7.0, followed by addition of ethanol $(50 / 50, \mathrm{v} / \mathrm{v})$ to precipitate alginate. After mixing, samples were centrifuged $(13,400 \mathrm{rpm} / 10 \mathrm{~min})$ and the supernatant was analysed to determine insulin content.

The concentration of insulin was determined by using a HPLC system (model HP1100 series, Hewlett Packard, Germany) equipped with an autosampler (Agilent 1100 series, Germany). A reversed-phase X-Terra C-18 column, $5 \mu \mathrm{m}$, $4.6 \mathrm{~mm} \times 250 \mathrm{~mm}$ (Waters, USA), with a Purospher ${ }^{\circledR}$ STAR RP18 precolumn, $5 \mu \mathrm{m}, 4 \mathrm{~mm} \times 4 \mathrm{~mm}$ (Merck, Germany) was employed. Mobile phase A consisted of $0.04 \%$ trifluoroacetic acid (TFA) in water and mobile phase B was $0.04 \%$ TFA in acetonitrile. A linear gradient of $30-40 \%$ B over 5 min was used with a flow rate of $1.2 \mathrm{ml} / \mathrm{min}$. Volumes of $20 \mu \mathrm{l}$ were injected, the UV detector was set at $210 \mathrm{~nm}$ and HPLC analysis was carried at $27^{\circ} \mathrm{C}$. A retention time of $4.5 \mathrm{~min}$ was obtained.

\subsubsection{Statistical analysis}

Each value was expressed as the mean \pm S.D. Statistical differences were analysed by using a one-way analysis of variance (ANOVA) followed by a Bonferroni post test. For a value of $P$ less than 0.05 the difference was considered significant. 


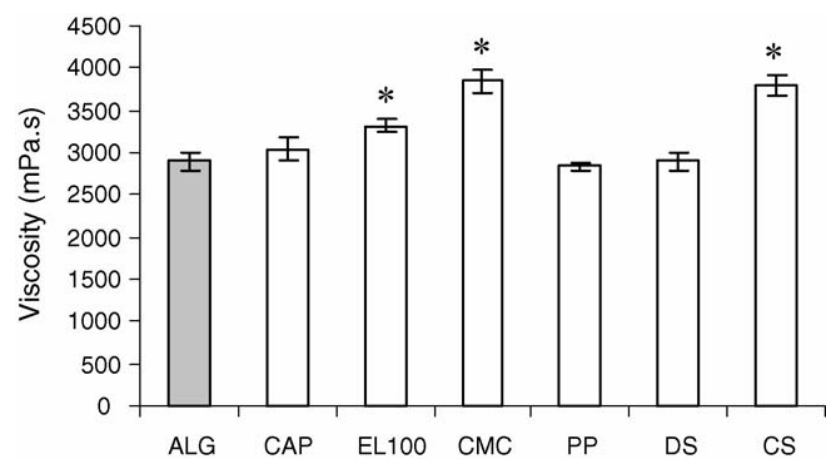

Fig. 1 - Viscosity of alginate: additive polymer blends before the encapsulation. ALG corresponds to the alginate solution at $2 \%(\mathrm{w} / \mathrm{v})$ without additive polymer. Polyanionic additive polymers were added to alginate solution at $0.5 \%$ (w/v). " $P<0.01$ by comparison with ALG.

\section{Results}

\subsection{Influence of matrix reinforcement}

Alginate at $2 \%(\mathrm{w} / \mathrm{v})$ was blended with another polyanion to decrease insulin leakage from microspheres during gastric passage but minimal effects on the size distribution and encapsulation efficiency of microspheres were desirable.

The influence on the viscosity of alginate solution at $2 \%$ caused by the addition of the additive polymers was calculated by measuring the viscosity of alginate: additive polymers blends before the emulsification step. Fig. 1 shows that the addition of CAP, PP and DS at $0.5 \%$ to the alginate solution at $2 \%$ did not change its viscosity $(P>0.05)$, while the addition of EL100, CMC and CS significantly increased the viscosity of alginate solution $(P<0.01)$.

Microspheres obtained from pure alginate (plain microspheres) showed a unimodal size distribution with a mean diameter value of $69 \mu \mathrm{m}$ and a SPAN factor of 0.8 (Table 1). When alginate was blended with CAP, PP and DS, no influence was detected on the mean diameter of microspheres, but the addition of EL100, CMC and CS caused an increase of mean diameter to near $100 \mu \mathrm{m}$. The SPAN factor increased with the mean diameter of microspheres. Despite differences on mean diameter caused by the addition of another polyanion to the alginate matrix, a unimodal size distribution was observed for all microspheres.
As illustrated in Fig. 2a, plain alginate microspheres were discrete and spherical in shape and no aggregation was observed. Tubular and star-like structures were visible on the microspheres and could be attributed to the presence of insulin, since they were not present in blank microspheres prepared without insulin (Fig. 2b). Fig. 3 shows that all additive polymer-blended microspheres were also composed of discrete and spherical microspheres. The presence of the tubular and star-like structures on the microspheres could be seen in all microspheres except when EL100, DS and CS were used as additive polymers.

To assess more relevant morphology differences among formulations, the surface of microspheres was examined by SEM (Fig. 4). Insulin was visible at the surface of alginate and PP microspheres, but it could not be detected at the surface of DS microspheres, which was in agreement with the previous optical microphotographs.

As shown in Fig. 5, the encapsulation efficiency of insulin was influenced by the addition of a polyanionic additive polymer to alginate matrix. A high encapsulation efficiency was obtained for plain alginate microspheres, near $86 \%$, and the insulin content was $4.7 \%(\mathrm{w} / \mathrm{w})$, corresponding to approximately $135 \mathrm{IU}$ per $100 \mathrm{mg}$ of microspheres. Lower encapsulation efficiencies of insulin $(P<0.001)$ were obtained for microspheres reinforced with CAP and EL100, 55.6 and 13.7\%, respectively. On the other hand, DS and CMC significantly increased the encapsulation efficiency of insulin $(P<0.05)$ and, in the case of DS, the encapsulation efficiency reached near $100 \%$.

Insulin release profile from microspheres, in gastrointestinal simulated $\mathrm{pH}$ conditions, is plotted in Fig. 6. Plain alginate microspheres showed an initial burst effect, at $\mathrm{pH}$ 1.2, reaching near $80 \%$ of total release. A fast and complete release of insulin occurred when microspheres were transferred to phosphate buffer at $\mathrm{pH} 6.8$ due to their dissolution. Alginate at $2 \%$ was blended with polyanions to avoid leakage of insulin at simulated gastric $\mathrm{pH}$. The percentage of insulin retention in microspheres after a 2-h incubation at pH 1.2 differed accordingly to the additive polymer blended with alginate. The addition of CMC to alginate matrix did not improve insulin retention $(P>0.05)$, while a slight increase of the insulin retention, up to $36 \%$, was observed for microspheres reinforced with CAP and EL100 $(P<0.01)$. For PP-reinforced microspheres, only $1 \%$ of the insulin was released at $\mathrm{pH} 1.2$, while for both DS and CS-reinforced alginate microspheres no insulin was detected in the acidic medium.

\section{Table 1 - Influence of the addition of a polyanionic additive polymer at $0.5 \%(\mathrm{w} / \mathrm{v})$ on the size distribution of alginate} microspheres

\begin{tabular}{llcr} 
Type of additive polymer & Abbreviation & Mean diameter ${ }^{\mathrm{a}}(\mu \mathrm{m})$ & SPAN factor \\
\hline- & ALG & $68.7 \pm 20.8$ & 0.82 \\
Cellulose acetate phthalate & CAP & $67.4 \pm 20.8$ & 0.84 \\
Eudragit ${ }^{\circledR}$ L100 & EL100 & $97.3 \pm 38.0$ & 0.92 \\
Sodium carboxymethylcellulose & CMC & $108.6 \pm 47.7$ & 1.16 \\
Polyphosphate & PP & $68.2 \pm 23.3$ & 0.89 \\
Dextran sulfate & DS & $71.3 \pm 22.9$ & 0.87 \\
Cellulose sulfate & CS & $105.7 \pm 42.2$ & 1.06 \\
\hline${ }^{a}$ Mean \pm S.D. & & & \\
\hline
\end{tabular}




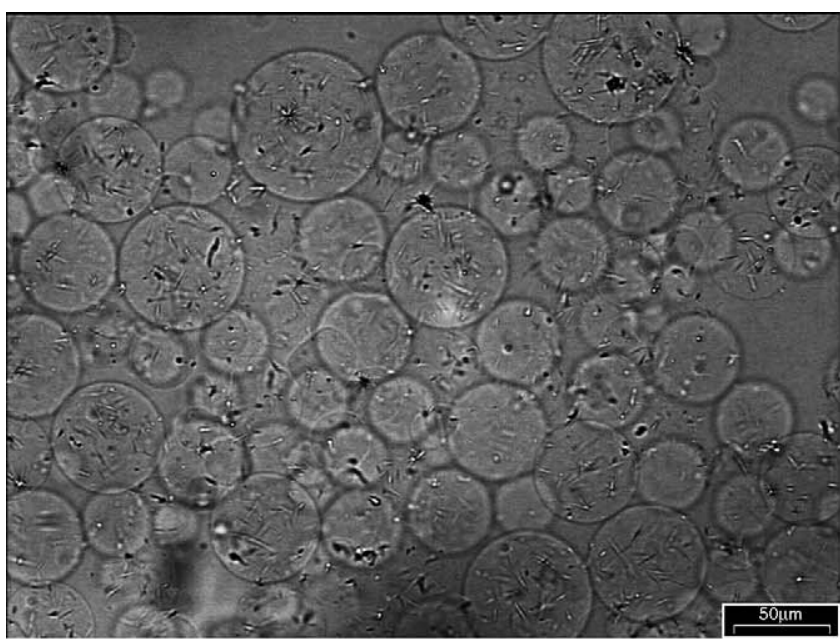

(a)

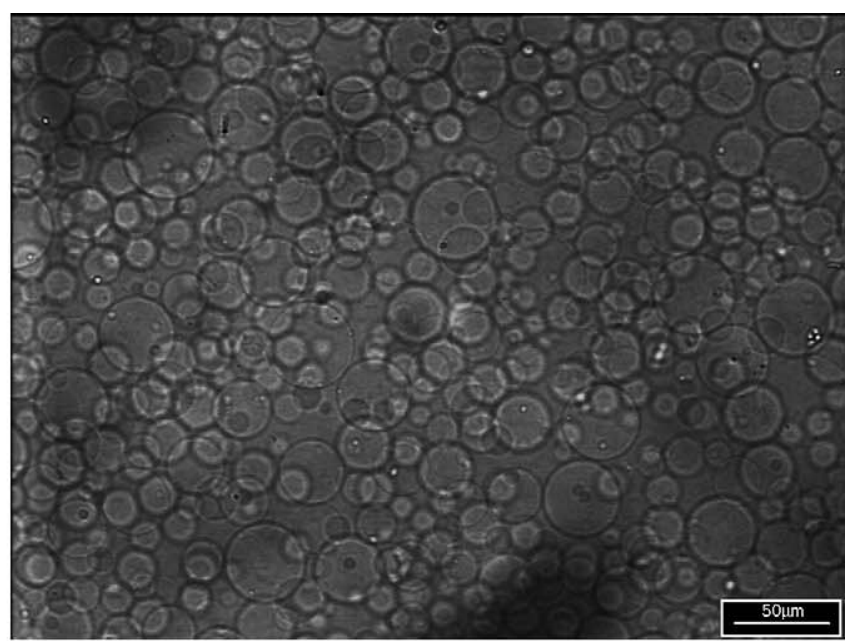

(b)

Fig. 2 - Optical microphotograph of plain insulin-loaded (a) and blank (b) alginate microspheres (magnification 200x).

When additive polymer-blended alginate microspheres were transferred to $\mathrm{pH} 6.8$, a fast dissolution of microspheres occurred for all formulations and insulin was completely released.

\subsection{Influence of chitosan-coating reinforced microspheres}

The previous results led us to study in more detail the microspheres containing DS and PP because they combined high encapsulation efficiencies with the preservation of the size distribution characteristics of microspheres and they were able to retain insulin release at simulated gastric $\mathrm{pH}$. In order to obtain a more sustained release of insulin from alginate microspheres, at simulated intestinal $\mathrm{pH}$, the effect of additive polymer concentration and chitosan-coating was evaluated.

Table 2 shows the effect of the additive polymer concentration and chitosan-coating on size distribution, insulin content and encapsulation efficiency of alginate microspheres. Increasing the additive polymer concentration from 0.5 to $1 \%$ caused no effect on mean diameter, although some tendency for aggregation was detected. Coated microspheres showed a slightly higher mean diameter size and SPAN factor owing to partially aggregation during the coating process.

No changes on the morphology of plain and additive polymer-blended microspheres, due to the presence of chitosan, were detected by optical microscopy (Fig. 7). Moreover, the increase of polyanion concentration caused no morphological differences on microspheres.

The increase of additive polymer concentration caused a slight decrease on insulin content of microspheres, which was more significant for microspheres reinforced with PP (Table 2). Nevertheless, the increase on additive polymer concentration corresponded to an increase on encapsulation efficiency. As described previously, insulin encapsulation efficiency is calculated from the ratio between the actual insulin content and the theoretical insulin content. When the amount of additive polymer increases, the theoretical insulin content will decrease, owing to the increase on the total theoretical polymer mass. For the microspheres containing additive polymer at 0.5 and $1 \%(\mathrm{w} / \mathrm{w})$, the theoretical insulin contents were 4.46 and $3.74 \%$, respectively, which gives the encapsulation

\begin{tabular}{|c|c|c|c|c|c|c|}
\hline Coating & $\begin{array}{l}\text { Type of } \\
\text { additive } \\
\text { polymer }\end{array}$ & $\begin{array}{c}\text { Additive polymer } \\
\text { concentration } \\
(\%, \mathrm{w} / \mathrm{v})\end{array}$ & $\begin{array}{c}\text { Mean diameter } \\
(\mu \mathrm{m})\end{array}$ & $\begin{array}{l}\text { SPAN } \\
\text { factor }\end{array}$ & $\begin{array}{l}\text { Insulin content } \\
(\%, w / w)\end{array}$ & $\begin{array}{l}\text { Encapsulation } \\
\text { efficiency }{ }^{\mathrm{a}} \\
(\%, \mathrm{w} / \mathrm{w})\end{array}$ \\
\hline \multirow{6}{*}{ Uncoated } & - & - & $68.7 \pm 20.8$ & 0.82 & $4.7 \pm 0.1$ & $85.6 \pm 2.3$ \\
\hline & \multirow{2}{*}{ PP } & 0.5 & $68.2 \pm 23.3$ & 0.89 & $4.2 \pm 0.1$ & $94.2 \pm 2.0$ \\
\hline & & 1.0 & $96.4 \pm 30.9$ & 0.87 & $3.8 \pm 0.2$ & $101.5 \pm 5.8$ \\
\hline & \multirow{2}{*}{ DS } & 0.5 & $71.3 \pm 22.9$ & 0.87 & $4.5 \pm 0.1$ & $101.2 \pm 1.5$ \\
\hline & & 1.0 & $85.4 \pm 24.4$ & 0.78 & $4.4 \pm 0.1$ & $117.3 \pm 2.0$ \\
\hline & - & - & $87.6 \pm 41.7$ & 1.24 & $4.5 \pm 0.2$ & $84.6 \pm 3.0$ \\
\hline \multirow{4}{*}{ Coated } & \multirow{2}{*}{ PP } & 0.5 & $84.7 \pm 29.1$ & 0.93 & $4.1 \pm 0.1$ & $94.4 \pm 3.1$ \\
\hline & & 1.0 & $72.3 \pm 25.0$ & 0.96 & $3.7 \pm 0.1$ & $102.0 \pm 2.4$ \\
\hline & \multirow{2}{*}{ DS } & 0.5 & $75.1 \pm 24.2$ & 0.89 & $4.1 \pm 0.1$ & $94.8 \pm 3.0$ \\
\hline & & 1.0 & $95.4 \pm 33.9$ & 0.97 & $4.0 \pm 0.1$ & $109.1 \pm 1.5$ \\
\hline
\end{tabular}


(a)
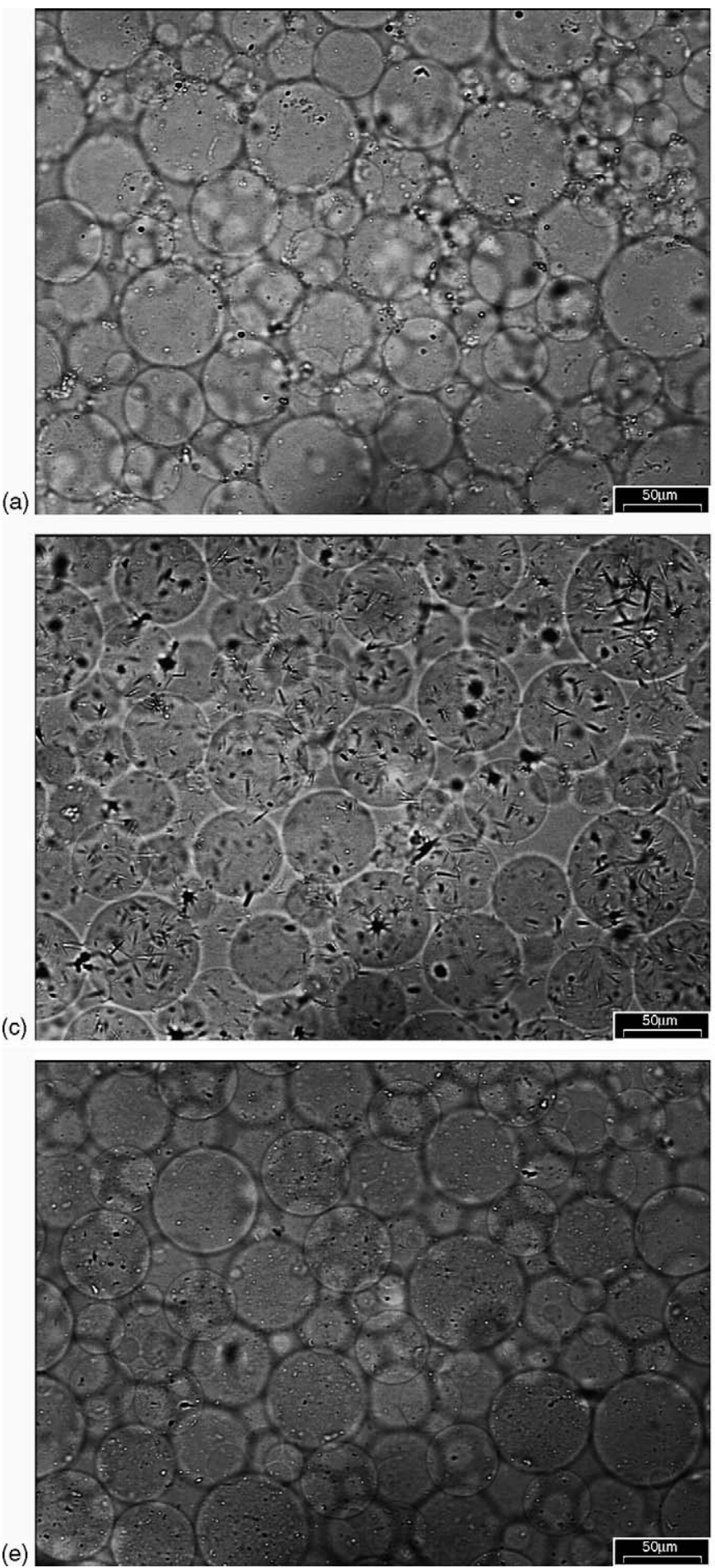

(b)

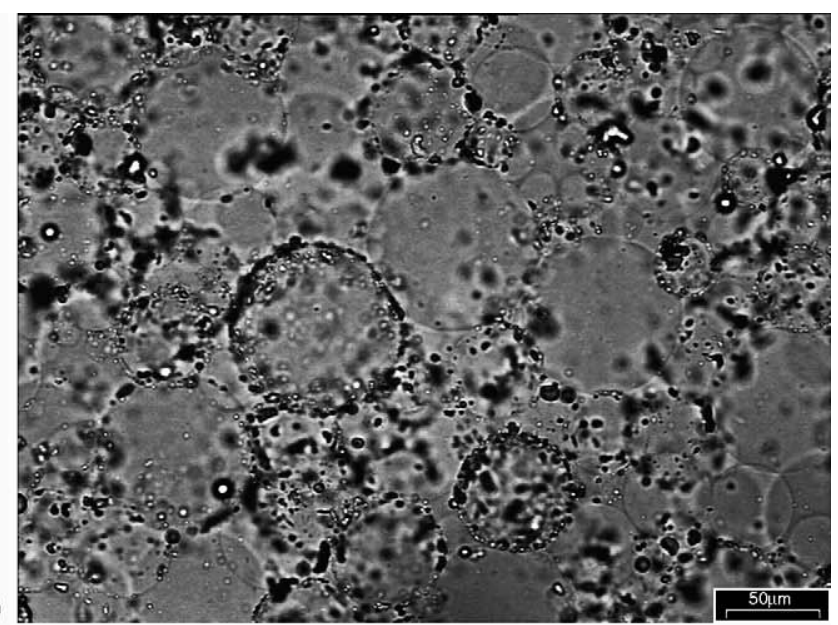

(d)
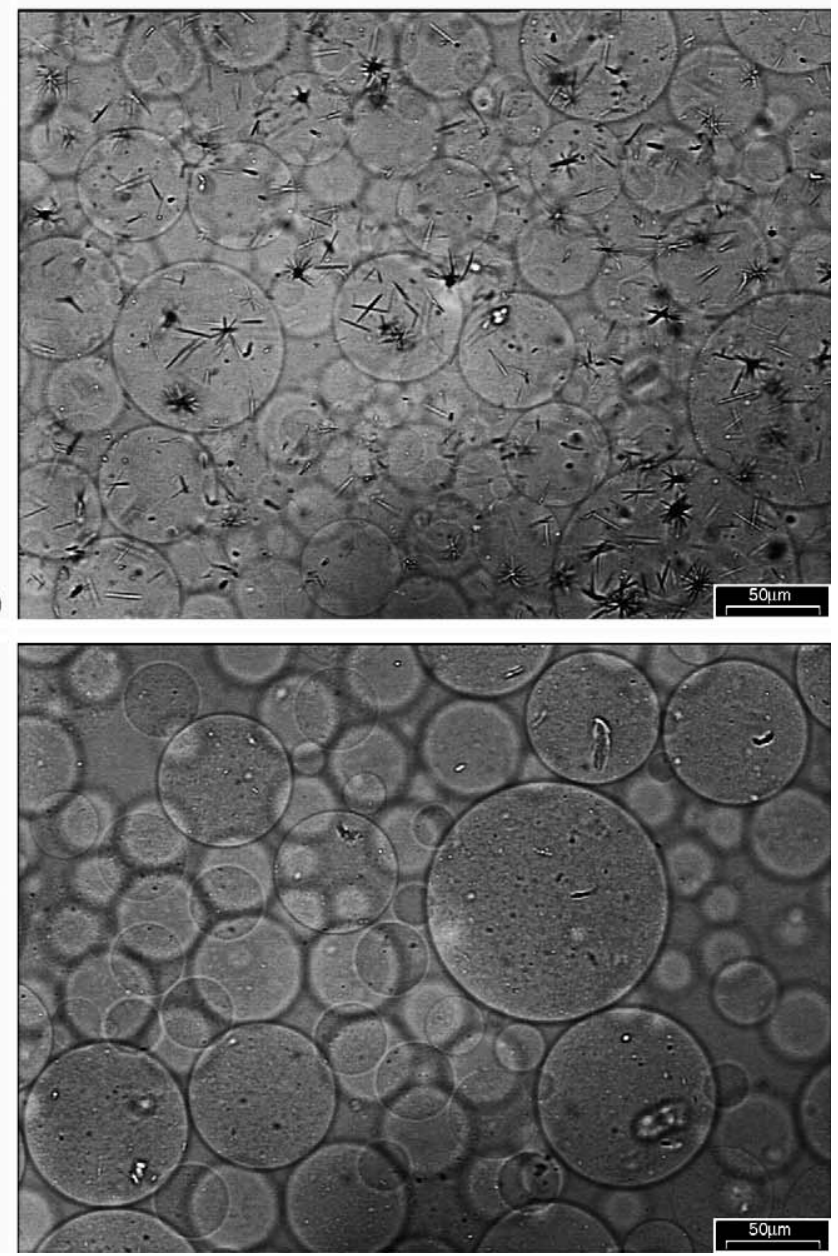

Fig. 3 - Optical microphotograph of insulin-loaded alginate microspheres containing (a) CAP, (b) EL100, (c) CMC, (d) PP, (e) DS or (f) CS at $0.5 \%(w / v)$ (magnification $200 x$ ).

efficiency values presented in Table 2.The increase on encapsulation efficiency was not significant for microspheres containing PP, but for microspheres with DS was very significant $(P<0.001)$. The attainment of encapsulation efficiencies higher than $100 \%$, especially when the additive polymer was added at a concentration of $1 \%(\mathrm{w} / \mathrm{w})$, can be explained by a partial loss of the additive polymer during the recovery of microspheres, which decreases the theoretical polymer mass and changes the theoretical insulin content to values higher than the previewed.

Coating the microspheres did not affect the insulin content of plain and reinforced alginate microspheres $(P>0.05)$. In terms of insulin encapsulation efficiency, similar results were obtained before and after chitosan-coating for plain 


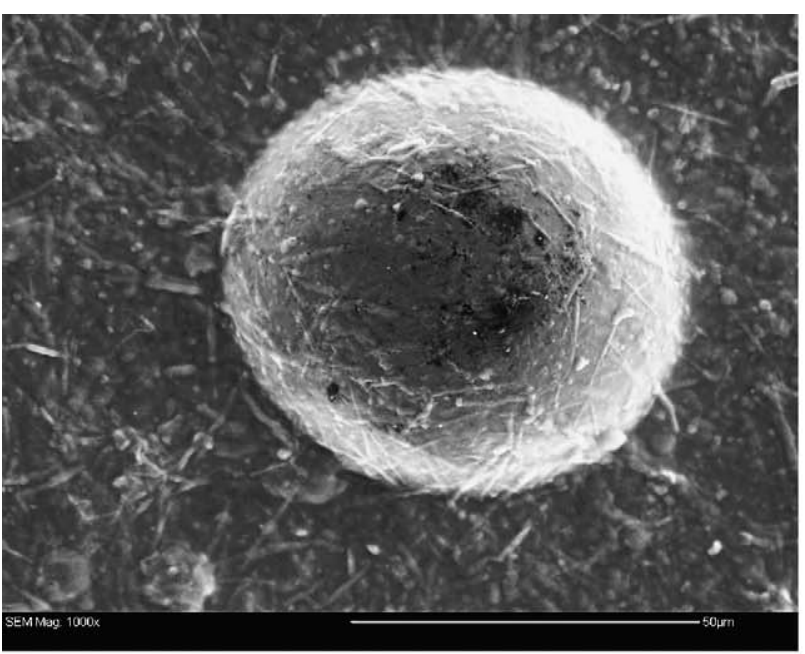

(a)

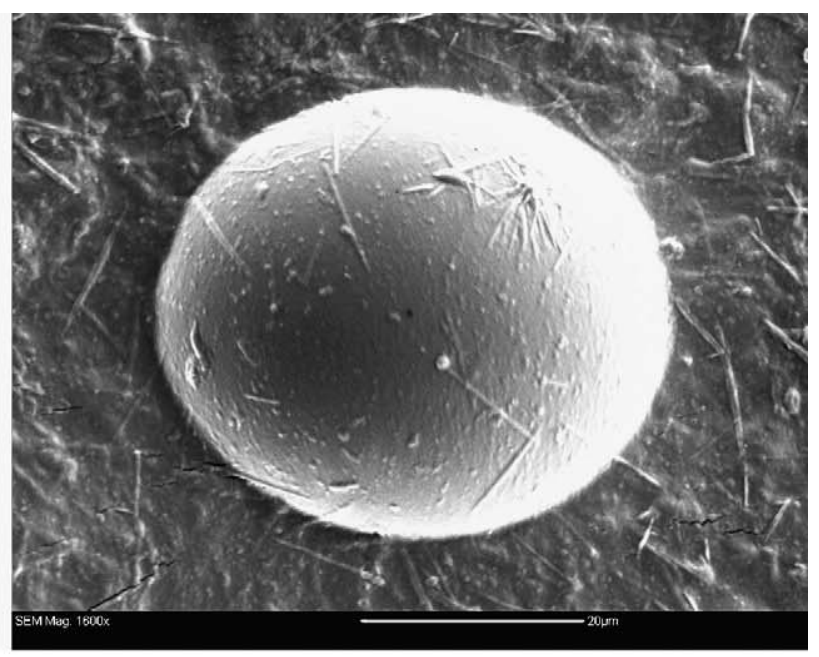

(b)

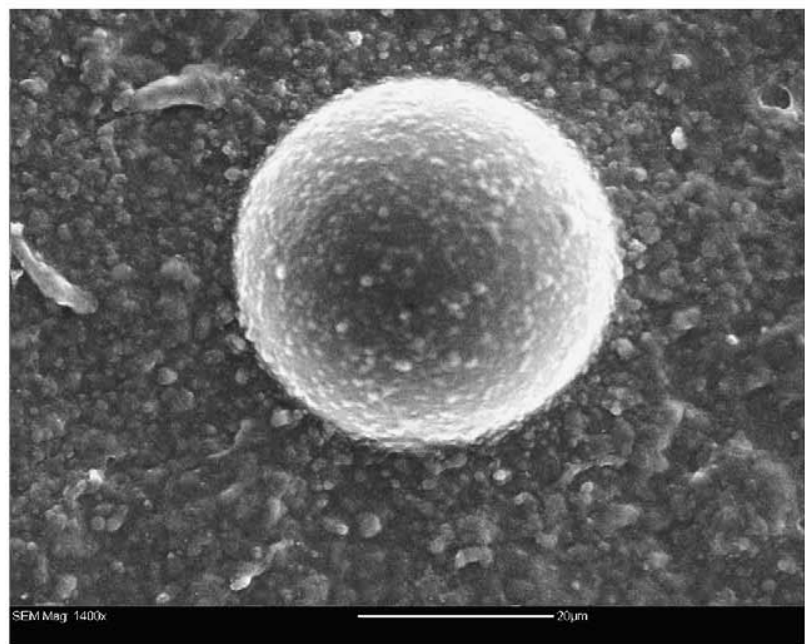

(c)

Fig. 4 - Surface morphology of (a) insulin-loaded alginate microspheres containing (b) PP or (c) DS at $0.5 \%$ (w/v) according to SEM micrograph (magnification 1000x).

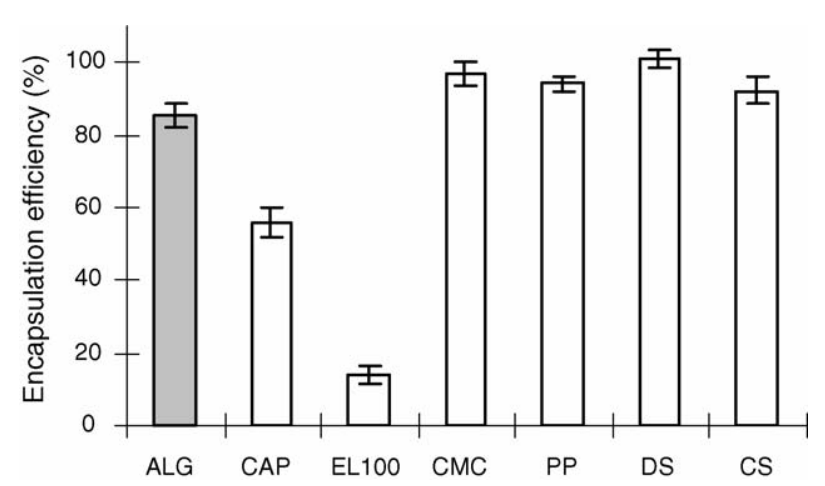

Fig. 5 - Insulin encapsulation efficiency in alginate microspheres (ALG) blended with a polyanionic additive polymer at $0.5 \%(w / v)$. Assays were performed in triplicate.

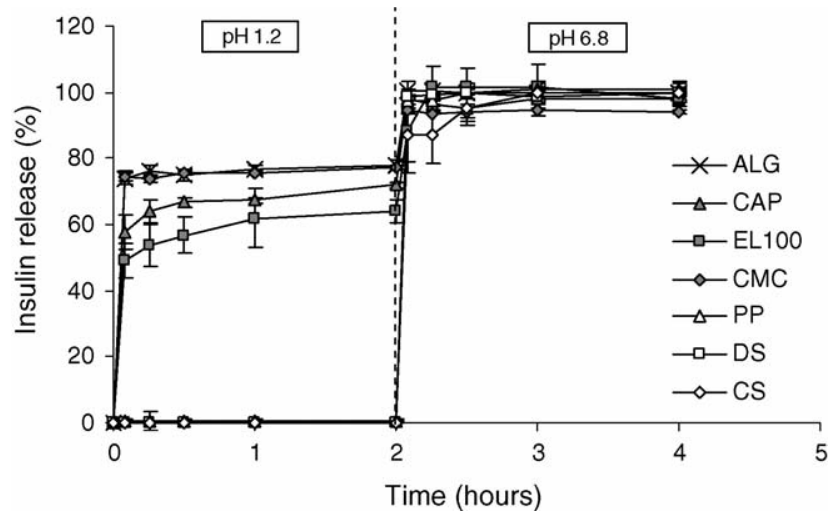

Fig. 6 - In vitro release profile of insulin from alginate microspheres (ALG) blended with a polyanionic additive polymer at $0.5 \%(\mathrm{w} / \mathrm{v})$. Microspheres were incubated at $\mathrm{pH}$ 1.2 for $2 \mathrm{~h}$ and then transferred to $\mathrm{pH}$ 6.8. The results are the mean of three experiments \pm S.D. 


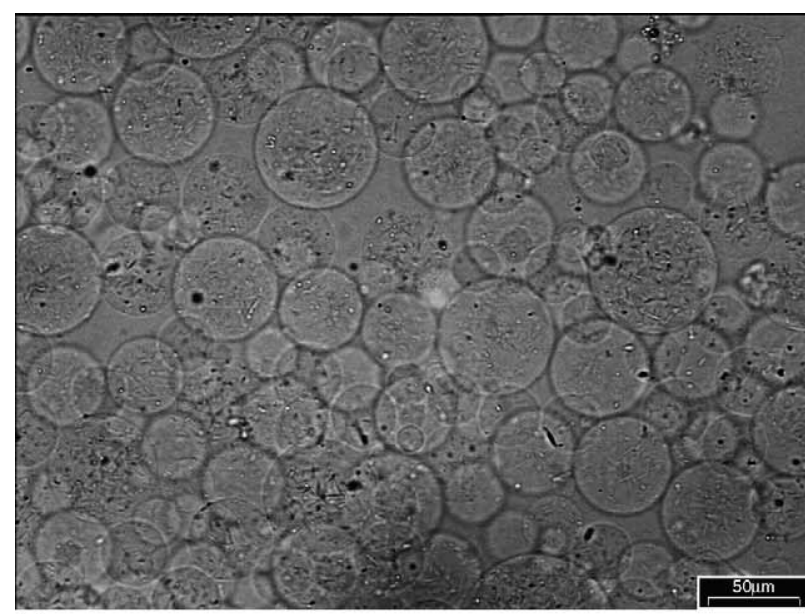

(a)

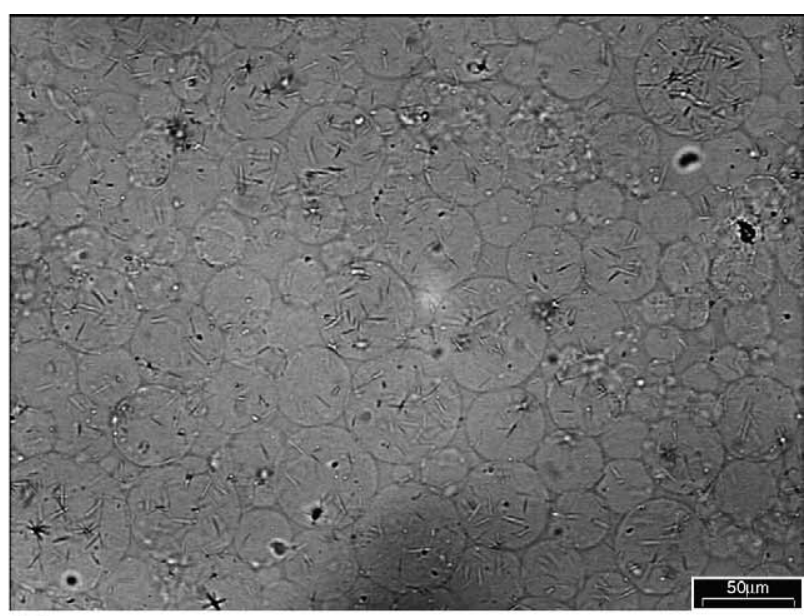

(b)

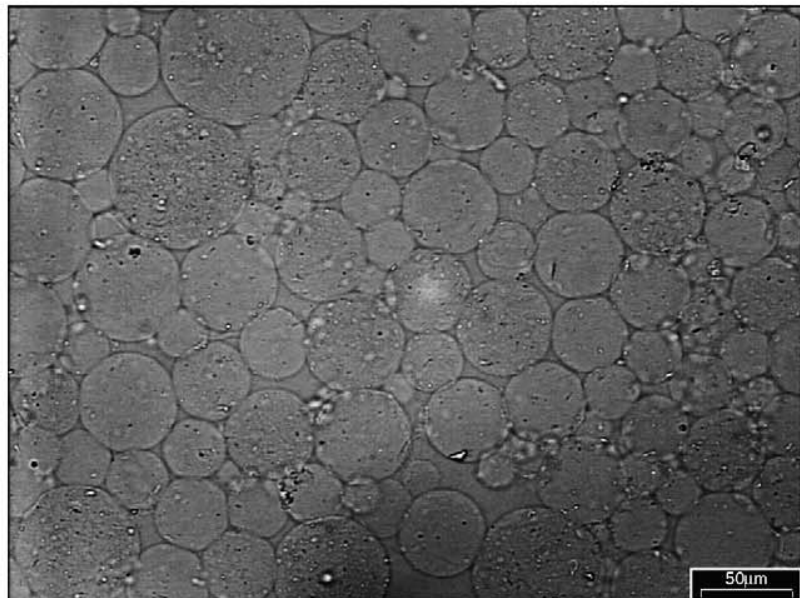

(c)

Fig. 7 - Optical microphotograph of (a) chitosan-coated insulin-loaded alginate microspheres containing (b) PP or (c) DS at $0.5 \%(w / v)$ (magnification 200x).

microspheres and microspheres reinforced with PP. For DSreinforced microspheres a significant decrease $(P<0.05)$ was observed after chitosan-coating, but insulin encapsulation efficiency was still higher than that obtained with plain microspheres $(P<0.05)$.

Chitosan-coating did not change the release profile of insulin from plain and DS-reinforced microspheres in simulated gastrointestinal $\mathrm{pH}$ conditions (Fig. 8). Interestingly, when microspheres containing PP at $0.5 \%$ were coated, insulin release increased from 1 to $11 \%$ after 2 -h incubation at $\mathrm{pH} 1.2$. At pH 6.8, coated microspheres did not dissolve and maintained their spherical shape; however a rapid and complete insulin release was obtained for all the formulations.

Furthermore, increasing the concentration of DS on microspheres did not induce changes on insulin release profile, for both uncoated and coated microspheres. In the case of PP, the increase on additive polymer concentration caused an increase on insulin release, after acid incubation, from 1 to $8 \%$ for uncoated microspheres, but when PP concentration was increased for coated microspheres, insulin release profile was not considerably changed. In respect to incubation at $\mathrm{pH} 6.8$, coated microspheres containing the highest concentration of

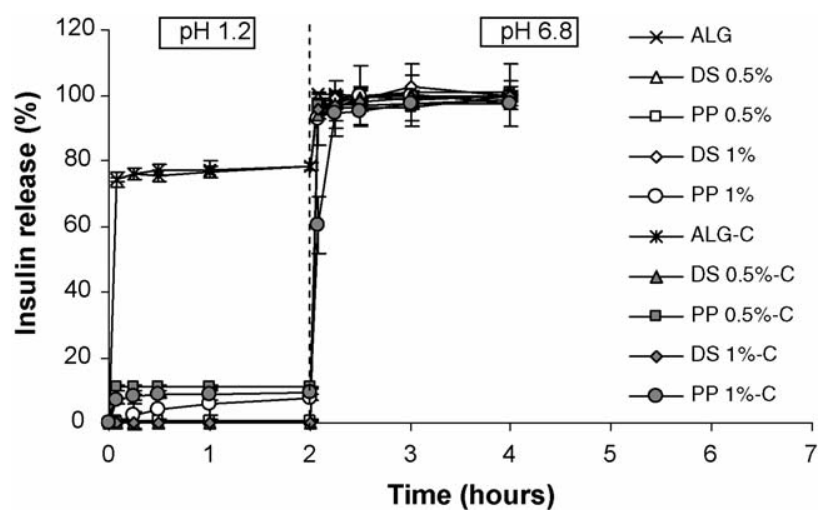

Fig. 8 - In vitro release profile of insulin from uncoated and chitosan-coated (C) microspheres reinforced with PP or DS at different concentrations. Microspheres were incubated at $\mathrm{pH} 1.2$ for $2 \mathrm{~h}$ and then transferred to $\mathrm{pH}$ 6.8. The results are the mean of three experiments \pm S.D. 
PP succeeded to retain near $40 \%$ of insulin just after changing the $\mathrm{pH}$ but then in few minutes an almost total release of the protein was achieved as observed for all the other formulations.

\section{Discussion}

The goal of this study was to develop insulin-loaded microspheres prepared by emulsification/internal gelation capable of retaining the protein in the matrix during the gastric passage and sustaining the insulin release at simulated intestinal $\mathrm{pH}$. Two strategies were assayed: the reinforcement of calcium alginate matrix with a polyanionic additive polymer and chitosan-coating of microspheres.

Several polyanions were studied and selected according to their suitability to prevent insulin release at simulated gastric $\mathrm{pH}$ and to their capacity of maintaining the size distribution of microspheres and the encapsulation efficiency of insulin. CAP and EL100 are commonly used as enteric polymers. CAP is a cellulose derivative that contains $21.5-26.0 \%$ of acetyl groups and 30.0-36.0\% of phthalyl groups. The molecular weight of CAP varies from 48 to $60 \mathrm{kDa}$ and the viscosity at $25^{\circ} \mathrm{C}$ is $45-90 \mathrm{mPa}$ s. EL100 is an anionic copolymer based on methacrylic acid and methyl methacrylate with a ratio of free carboxyl groups to the ester groups of 1:1, soluble at $\mathrm{pH}>6$. The average molecular weight of EL100 is $135 \mathrm{kDa}$ and the viscosity at $20^{\circ} \mathrm{C}$ is $50-200 \mathrm{mPa}$. CMC is a sodium salt of a polycarboxymethyl ether of cellulose, which has a typical molecular weight of $90-700 \mathrm{kDa}$ and a $\mathrm{pK}_{\mathrm{a}}$ value of 4.3 . Low viscosity CMC may have a viscosity between 10 and $110 \mathrm{mPas}$. PP or sodium hexametaphosphate is a linear condensed phosphate with an average chain length of 12 and a molecular weight of approximately $1.3 \mathrm{kDa}$. DS is a branched glucose polymer containing approximately 2.3 sulfate groups per glucosyl residue and having a molecular weight of near $5 \mathrm{kDa}$. CS is a sulfated cellulose derivative with a degree of substitution of 1.5-2.8 sulfate groups per glucosyl residue and a molecular weight of $2900 \mathrm{kDa}$.

The reinforcement of alginate matrix with CAP, PP and DS permitted the maintenance of the mean diameter of microspheres. The size distribution of microspheres prepared by an emulsification methodology is related to the internal phase viscosity (Bahukudumbi et al., 2004) but the effect of one polymer on the viscosity of another polymer depends on many factors. In our study, following the addition of CAP, PP and DS, no effect was observed on the viscosity of alginate solution and, consequently, differences on mean size were not observed. In previous studies, it was observed that the addition of a cellulose derivative to alginate caused an increase on the solution viscosity and on mean size (Chan et al., 1997), while the viscosity of a starch solution was greatly decreased by the addition of gums, attributed to repelling forces between the phosphate groups on starch and the negative charges on molecules of these gums (Shi and BeMiller, 2002). Interestingly, in another study, the incorporation of Eudragit ${ }^{\circledR}$ L100 55 into alginate microspheres prepared by emulsification had no effect on the size (Gursoy et al., 1999).

Another goal of this study was the attainment of high insulin encapsulation efficiencies, which was achieved with the majority of the additive polymers. The increase on insulin encapsulation efficiency in the microspheres can have two explanations: the incorporation of an additive polymer can create a higher network density or an electrostatic interaction between the protein and the polyanions may favour the retention of insulin in the microspheres.

Higher encapsulation efficiencies were obtained for microspheres containing DS and CS, but no insulin was observed on these microspheres by using optical microscopy. We may suppose that the protein is located inside the microspheres and not at its surface, revealing a different type of interaction of these polymers with insulin or a different type of polymer network, possibly related to its higher negative net charge. This more interior location of insulin in DS- and CS-reinforced microspheres may be favourable for protecting insulin against enzymatic degradation.

PP, DS and CS were the most efficient additive polymers in avoiding insulin release in acidic medium. A higher release of insulin was obtained for microspheres reinforced with EL100, CAP and CMC. Eudragit ${ }^{\circledR}$ L100 and CAP, insoluble in acids but soluble at intestinal $\mathrm{pH}$, have been used as enteric polymers and their incorporation into dipyridamole-loaded alginate gel microspheres (1:1) (Gursoy et al., 1999) and diclofenac-loaded calcium alginate-pectinate matrix (0.2-1:1) (Pillay et al., 2002), respectively, did not decrease drug release from microspheres in acidic medium. Low viscosity CMC slightly decreased the rate of sulphaguanidine release from microspheres composed of alginate:CMC (7:3) (Chan et al., 1997), possibly due to the formation of insoluble CaCMC which formed a less permeable barrier to drug diffusion. To our knowledge DS and PP were never used to reinforce alginate microspheres in order to control drug release profile. CS has been used in the formation of multicomponent polyelectrolyte systems of alginate/CS and calcium/poly(methylene-co-guanidine) hydrochloride (Wang et al., 1997), but this system has only been applied for the encapsulation of cells (Bartkowiak et al., 1999; Canaple et al., 2001; Zhang et al., 2005).

The incubation of calcium alginate microspheres, at $\mathrm{pH}$ 1.2, causes calcium ions to be displaced from the polymer network and the calcium alginate gel is converted to the unionized form of alginic acid (Ostberg et al., 1994). This may lead to dissociation of ionic linkages and reduction in the gel strength that may favour insulin release by diffusion. On the other hand, during the recovery of microspheres, at $\mathrm{pH} 4.5$, probably occurs an interaction between the negatively charged alginate and the positively charged insulin (Silva et al., 2005). However, at $\mathrm{pH} 1.2$, this interaction should be affected by the possible alginate precipitation in the form of alginic acid and a high insulin release results from the incubation of plain alginate microspheres at $\mathrm{pH}$ 1.2.

The addition of another polyanion to alginate matrix increases the polymer concentration which may result in a higher network density, but the effect observed on insulin release at $\mathrm{pH} 1.2$, seemed to be mainly due to electrostatic interactions. The dissociation constants for mannuronic and guluronic acid monomers of alginate are 3.38 and 3.65, respectively (Draget et al., 2005). In the case of DS and CS, the sulfate groups are considered to be permanently charged since they are known to have a negative first $\mathrm{pK}_{\mathrm{a}}$ value and a second $\mathrm{p} \mathrm{K}_{\mathrm{a}}$ value of near 2 . The physical mixture of alginate with DS or 
CS provides both $\mathrm{pH}$-sensitive (carboxylic) and permanently charged (sulfate) groups. The presence of permanent negative charges may be responsible for interacting with insulin (isoelectric point, $\mathrm{pI}=5.3-5.4$ ) at acidic $\mathrm{pH}$, thus preventing its release. PP also demonstrated ability to prevent insulin release at $\mathrm{pH}$ 1.2. It is known that phosphoric acid has three $\mathrm{pK}_{\mathrm{a}}$ values at 2.2, 7.2 and 12.3, but in PP the number of $\mathrm{pK}_{\mathrm{a}}$ values will be higher accordingly to the number of phosphate units. It is possible that at $\mathrm{pH} 1.2$ there are still some negative charges for interaction with insulin, although this interaction should be weaker than that observed with sulfate groups. In the case of EL100, CAP and CMC, the negative charges of these polyanions are due to carboxylic groups and probably they behave like alginate. Based on the above considerations it can be assumed that the structural differences between the additive polymers are likely to affect the interaction with insulin.

Successful oral sustained-release formulation is dependent on the sequential changes of environment through the gastrointestinal tract, as it passes from the strongly acidic $\mathrm{pH}$ 1-3) to the weakly alkaline ( $\mathrm{pH}$ 6.5-7.5) medium in the lower part of the small intestine. After changing to $\mathrm{pH} 6.8$, a complete and fast dissolution of microspheres occurred for all uncoated formulations because the alginic acid formed during acid incubation was converted to a soluble salt of sodium alginate. This causes the matrix to swell and disintegrate, enabling the complete and fast release of insulin. Moreover, the reinforcement of alginate microspheres with the polyanionic additive polymers did not improve insulin release at $\mathrm{pH}$ 6.8. In fact, increasing the $\mathrm{pH}$ to a value higher than insulin $\mathrm{pI}$ causes the reversion of the interaction with the negatively charged groups of the additive polymers.

The best results of gastric release studies were obtained with microspheres containing PP, DS and CS, but considering the preservation of size distribution and maintenance of high insulin encapsulation, DS and PP were chosen for further studies. CS increased the mean diameter of microspheres and had lower encapsulation efficiency than DS. These two polymers are both composed of glucose units containing sulfate groups, but DS is a branched chain polysaccharide of near $5 \mathrm{kDa}$, while CS is a linear polymer with near $2900 \mathrm{kDa}$. The higher molecular weight of CS accounts for a higher viscosity in solution and justifies the increase on mean size. On the other hand, the low molecular weigh of dextran sulfate, near that of insulin $(5.8 \mathrm{kDa})$ may favour the interaction between them and contribute to increase the insulin retention in microspheres.

A sustained release of insulin at $\mathrm{pH} 6.8$ would also be desirable to reduce the potential degradation of insulin before absorption. In an attempt to achieve a sustained release of insulin from microspheres at simulated intestinal $\mathrm{pH}$, the polyanion concentration was increased but it did not give better results. It could be expected that a higher network density could decrease the permeability of microspheres' matrix. However, such effect was not observed since no suppression of the initial release of insulin, at pH 6.8, was obtained.

Another strategy used in this study to improve insulin release profile at $\mathrm{pH} 6.8$ was chitosan-coating alginate microspheres containing DS or PP. The similar release profile at $\mathrm{pH}$ 6.8 obtained for coated microspheres could be explained by the fact that chitosan formed a high porous polyelectrolyte complex membrane that did not act as a diffusion barrier. In fact, chitosan-coated microspheres coated were still spherical and did not dissolve after incubation at $\mathrm{pH}$ 6.8. Although it was possible to prevent the disintegration of microspheres, insulin release at this $\mathrm{pH}$ was still very fast. Chitosan has an apparent $\mathrm{pK}_{\mathrm{a}}$ of 6.3 and assumes a stiff extended conformation in aqueous media of low $\mathrm{pH}$ due to the charge repulsion of highly protonated amino groups, but it becomes increasingly globular as pH increases (Ma et al., 2002). Therefore, at pH 6.8, the resulting polymer shrinkage manifests as increased membrane pore size, resulting in a microporous membrane (Okhamafe et al., 1996). This may account for the rapid protein elution at simulated intestinal $\mathrm{pH}$.

In previous studies, chitosan-coating was able to decrease the gel erosion (Murata et al., 1993) and allow a drug sustained release (Polk et al., 1994; Sezer and Akbuga, 1999) from alginate microspheres. However, in our study, uncoated and chitosancoated alginate microspheres showed the same release profile. These contradictory results may be related to differences in the preparation procedures, the composition of chitosan and the composition and structure of the alginate gels (Gaserod et al., 1998; Shu and Zhu, 2002).

Surprisingly, in the case of PP, an increase on insulin release at pH 1.2 was obtained when microspheres were chitosan coated. This result could be reasonably attributed to a competition between chitosan and the positively charged insulin for PP. This polyanion has been used to cross-link chitosan in the preparation of microspheres due to the formation of a strong interpolymer complex between $-\left[\mathrm{P}_{2} \mathrm{O}_{5}{ }^{4-}\right]-$ and $-\mathrm{NH}_{3}{ }^{+}$groups of PP and chitosan, respectively (Mi et al., 1999; Angelova and Hunkeler, 2001). The same effect was not observed for DS, also known to interact with chitosan (Chen et al., 2003), which can be due to a stronger interaction between DS and insulin that retains the protein in the formulation.

Notwithstanding, the presence of chitosan may be important for improving insulin intestinal absorption due to its mucoadhesive properties that prolongs the residence time of the dosage form in the intestine. Mucoadhesive polymers are also able to reduce the enzymatic barrier by sticking to the mucus layer at the site of drug absorption, thereby decreasing the distance between the released therapeutic peptide from the dosage form and the absorptive tissue (BernkopSchnurch, 1998). Moreover, chitosan has been described for its capacity of enhancing absorption of various compounds across the mucosal barrier via the paracellular transport pathway (Artursson et al., 1994; Smith et al., 2004). Chitosan-coated alginate microspheres, in particular, have shown to increase the paracellular permeability of Lucifer Yellow, a permeability marker, across Caco-2 cell monolayers (Silva et al., unpublished data).

In conclusion, insulin-loaded alginate microspheres' formulation was optimized in order to prevent insulin release at gastric $\mathrm{pH}$. The incorporation of DS into the alginate matrix increased the encapsulation efficiency of insulin without affecting the mean diameter of microspheres and prevented insulin release at $\mathrm{pH}$ 1.2. The stability of the microspheres may be due to an electrostatic interaction between the protein and the polyanion. In respect to achieving a more sustained release of insulin at simulated intestinal $\mathrm{pH}$, neither the increase of the additive polymer concentration, nor chitosan-coating additive polymer-reinforced microspheres were efficient. Fur- 
ther studies are needed to achieve this target and the improved formulation should be tested for its ability to protect insulin from proteolytic degradation. Nevertheless, chitosan-coated DS-reinforced microspheres may be good candidates for oral delivery of insulin, since the presence of chitosan may promote insulin absorption through the intestinal epithelia and this needs further confirmation by in vivo studies.

\section{Acknowledgements}

This research was financially supported by a grant from the Fundação para a Ciência e Tecnologia (FCT) of Portugal (SFRH/BD/5085/2001). The authors would like to thank Eng. Vítor Redondo and Prof. Margarida Figueiredo from Instituto Pedro Nunes (Coimbra, Portugal) for size distribution determination and Professor A. Rocha Gonçalves from Departamento de Química, Faculdade de Ciências e Tecnologia, Universidade de Coimbra (Coimbra, Portugal) for HPLC equipment.

\section{REF E R E N C E S}

Almeida, P.F., Almeida, A.J., 2004. Cross-linked alginate-gelatine beads: a new matrix for controlled release of pindolol. J. Control. Rel. 97, 431-439.

Anal, A.K., Stevens, W.F., 2005. Chitosan-alginate multilayer beads for controlled release of ampicilin. Int. J. Pharm. 290, 45-54.

Angelova, N., Hunkeler, D., 2001. Effect of preparation conditions on properties and permeability of chitosan-sodium hexametaphosphate capsules. J. Biomater. Sci. Polym. Ed. 12, 1317-1337.

Arbit, E., 2004. The physiological rationale for oral insulin administration. Diabetes Technol. Ther. 6, 510-517.

Artursson, P., Lindmark, T., Davis, S.S., Illum, L., 1994. Effect of chitosan on the permeability of monolayers of intestinal epithelial cells (Caco-2). Pharm. Res. 11, 1358-1361.

Bahukudumbi, P., Carson, K.H., Rice-Ficht, A.C., Andrews, M.J., 2004. On the diameter and size distributions of bovine serum albumin (BSA)-based microspheres. J. Microencapsul. 21, 787-803.

Bartkowiak, A., Canaple, L., Ceasoglu, I., Nurdin, N., Renken, A., Rindisbacher, L., Wandrey, C., Desvergne, B., Hunkeler, D., 1999. New multicomponent capsules for immunoisolation. Ann. NY Acad. Sci. 875, 135-145.

Bernkop-Schnurch, A., 1998. The use of inhibitory agents to overcome the enzymatic barrier to perorally administered therapeutic peptides and proteins. J. Control. Rel. 52, 1-16.

Brange, J., Langkjaer, L., 1997. Insulin formulation and delivery. In: Sanders, L.M., Hendren, R.W. (Eds.), Protein Delivery: Physical Systems. Plenum Press, New York, pp. 343-410.

Canaple, L., Nurdin, N., Angelova, N., Hunkeler, D., Desvergnea, B., 2001. Development of coculture model of encapsulated cells. Ann. NY Acad. Sci. 944, 350-361.

Carino, G.P., Mathiowitz, E., 1999. Oral insulin delivery. Adv. Drug Deliv. Rev. 35, 249-257.

Chan, L.W., Heng, P.W., 1998. Effects of poly(vinylpyrrolidone) and ethylcellulose on alginate microspheres prepared by emulsification. J. Microencapsul. 15, 409-420.

Chan, L.W., Heng, P.W., Wan, L.S., 1997. Effect of cellulose derivatives on alginate microspheres prepared by emulsification. J. Microencapsul. 14, 545-555.

Chen, Y., Mohanraj, V.J., Parkin, J.E., 2003. Chitosan-dextran sulfate nanoparticles for delivery of an anti-angiogenesis peptide. Lett. Peptide Sci. 10, 621-629.
Chickering, D.E., Jacob, J.S., Desai, T.A., Harrison, M., Harris, W.P., Morrell, C.N., Chaturvedi, P., Mathiowitz, E., 1997. Bioadhesive microspheres. III. "In vivo" transit and bioavailability study of drug-loaded alginate and poly(fumaric-co-sebacic anhydride) microspheres. J. Control. Rel. 48, 35-46.

Cui, J.H., Goh, J.S., Park, S.Y., Kim, P.H., Le, B.J., 2001. Preparation and physical characterization of alginate microparticles using air atomization method. Drug Dev. Ind. Pharm. 27, 309-319.

Draget, K.I., Smidsrod, O., Skjak Braek, G., 2005. Alginates from algae. In: Steinbuchel, A., Rhee, S.K. (Eds.), Polysaccharides and Polyamides in the Food Industry: Properties, Production and Patents. Wiley-VCH, Weinheim, pp. 1-30.

El-Kamel, A.H., Al-Gohary, O.M.N., Hosny, E.A., 2003. Alginate-diltiazem hydrochloride beads: optimization of formulation factors, in vitro and in vivo availability. J. Microencapsul. 20, 211-225.

El-Mahdy, M., Ibrahim, E.S., Safwat, S., El-Sayed, A., Ohshima, H., Makino, K., Muramatsu, N., Kondo, T., 1998. Effects of preparation conditions on the monodispersity of albumin microspheres. J. Microencapsul. 15, 661-673.

Gaserod, O., Smidsrod, O., Skjak-Braek, G., 1998. Microcapsules of alginate-chitosan. I. A quantitative study of the interaction between alginate and chitosan. Biomaterials 19, 1815-1825.

Gursoy, A., Cevik, S., 2000. Sustained release properties of alginate microspheres and tabletted microspheres of diclofenac sodium. J. Microencapsul. 17, 565-575.

Gursoy, A., Karakus, D., Okar, I., 1999. Polymers for sustained release formulations of dipyridamole-alginate microspheres and tabletted microspheres. J. Microencapsul. 16, 439-452.

Iruin, A., Fernandez-Arevalo, M., Alvarez-Fuentes, J., 2005. Elaboration and in vitro characterization of 5-ASA beads. Drug Dev. Ind. Pharm. 31, 231-239.

Lehr, C.-M., Bouwstra, J.A., Schacht, E.H., Junginger, H.E., 1992. In vitro evaluation of mucoadhesive properties of chitosan and some other natural polymers. Int. J. Pharm. 78, 43-48.

Ma, Z., Yeoh, H.H., Lim, L.-Y., 2002. Formulation pH modulates the interaction of insulin with chitosan nanoparticles. J. Pharm. Sci. 91, 1396-1404.

Mi, F.L., Shyu, S.S., Kuan, C.Y., Lee, S.T., Lu, K.T., Jang, S.F., 1999. Chitosan-polyelectrolyte complexation for the preparation of gel beads and controlled release of anticancer drug. I. Effect of phosphorous polyelectrolyte complex and enzymatic hydrolysis of polymer. J. Appl. Polym. Sci. 74, 1868-1879.

Murata, Y., Maeda, T., Miyamoto, E., Kawashima, S., 1993. Preparation of chitosan-reinforced alginate gel beads-effects of chitosan on gel matrix erosion. Int. J. Pharm. 96, 139-145.

Murata, Y., Miyamoto, E., Kawashima, S., 1996. Additive effect of chondroitin sulfate and chitosan on drug release from calcium-induced alginate gel beads. J. Control. Rel. 38, 101-108.

Murata, Y., Tsumoto, K., Kofuji, K., Kawashima, S., 2003. Effects of natural polysaccharide addition on drug release from calcium-induced alginate gel beads. Chem. Pharm. Bull. 51, 218-220.

Okhamafe, A.O., Amsden, B., Chu, W., Goosen, M.F., 1996. Modulation of protein release from chitosan-alginate microcapsules using the $\mathrm{pH}$-sensitive polymer hydroxypropyl methylcellulose acetate succinate. J. Microencapsul. 13, 497-508.

Ostberg, T., Lund, E.M., Graffner, C., 1994. Calcium alginate matrices for oral multiple unit administration. IV. Release characteristics in different media. Int. J. Pharm. 112, 241-248.

Pillay, V., Danckwerts, M.P., Fassihi, R., 2002. A cross-linked calcium-alginate-pectinate-cellulose acetophtalate gelisphere system for linear drug release. Drug Deliv. 9, 77-86.

Pillay, V., Danckwerts, M.P., Muhiddinov, Z., Fassihi, R., 2005. Novel modulation of drug delivery using binary zinc-alginate-pectinate polyspheres for zero-order kinetics over several days: experimental design strategy to elucidate 
the crosslinking mechanism. Drug Dev. Ind. Pharm. 31, 191-207.

Polk, A., Amsden, B., De Yao, K., Peng, T., Goosen, M.F., 1994. Controlled release of albumin from chitosan-alginate microcapsules. J. Pharm. Sci. 83, 178-185.

Ribeiro, A.J., Silva, C., Ferreira, D., Veiga, F., 2005. Chitosan-reinforced alginate microspheres obtained through the emulsification/internal gelation technique. Eur. J. Pharm. Sci. 25, 31-40.

Sezer, A.D., Akbuga, J., 1999. Release characteristics of chitosan treated alginate beads. I. Sustained release of a macromolecular drug from chitosan treated alginate beads. J. Microencapsul. 16, 195-203.

Shi, X., BeMiller, J.N., 2002. Effects of food gums on viscosities of starch suspensions during pasting. Carbohydr. Polym. 50, 7-18.

Shu, X.Z., Zhu, K.J., 2002. The release behavior of brilliant blue from calcium-alginate gel beads coated with chitosan: the preparation method effect. Eur. J. Pharm. Biopharm. 53, 193-201.

Silva, C.M., Ribeiro, A.J., Figueiredo, I.V., Rocha Gonçalves, A., Veiga, F., 2006. Alginate microspheres prepared by internal gelation: development and effect on insulin stability. Int. J. Pharm. 311, 1-10.
Silva, C.M., Ribeiro, A.J., Figueiredo, M., Ferreira, D., Veiga, F., 2005. Microencapsulation of $\mathrm{Hb}$ in chitosan-coated alginate microspheres prepared by emulsification/internal gelation. AAPS J. 7, article 88.

Smith, J., Wood, E., Dornish, M., 2004. Effect of chitosan on epithelial cell tight junctions. Pharm. Res. 21, 43-49.

Sood, A., Panchagnula, R., 2001. Peroral route: an opportunity for protein and peptide drug delivery. Chem. Rev. 101, 3275-3303.

Ueng, S.W.N., Yuan, L.J., Lee, N., Lin, S.S., Chan, E.C., Weng, J.H., 2004. In vivo study of biodegradable alginate antibiotic beads in rabbits. J. Orthop. Res. 22, 592-599.

van de Weert, M., Hennink, W.E., Jiskoot, W., 2000. Protein instability in poly(lactic-co-glycolic acid) microparticles. Pharm. Res. 17, 1159-1167.

Wang, T., Lacik, I., Brissova, M., Anilkumar, A.V., Prokop, A., Hunkeler, D., Green, R., Shahrokhi, K., Powers, A.C., 1997. An encapsulation system for the immunoisolation of pancreatic islets. Nat. Biotechnol. 15, 358-362.

Zhang, L.Y., Yao, S.J., Guan, Y.X., 2005. Effects of poly(methylene-co-guanidine) on microbial growth in an alginate/cellulose sulphate- $\mathrm{CaCl}_{2} /$ poly(methylene-co-guanidine) capsule system. Process Biochem. 40, 189-193. 